\title{
Examination of fabrication conditions of acrylate-based hydrogel formulations for doxorubicin release and efficacy test for hepatocellular carcinoma cell
}

\author{
Gulay Bayramoglu ${ }^{\mathrm{a}, \mathrm{b} *}$, Damla Gozen ${ }^{\mathrm{c}}$, Gozde Ersoy ${ }^{\mathrm{a}}$, V. Cengiz Ozalp ${ }^{\mathrm{d}}$, \\ K. Can Akcali ${ }^{\mathrm{b}}$ and M. Yakup Arica ${ }^{\mathrm{a}}$ \\ ${ }^{a}$ Faculty of Sciences, Biochemical Processing and Biomaterial Research Laboratory, \\ Gazi University, 06500 Teknikokullar-Ankara, Turkey; ${ }^{b}$ Faculty of Science, Department of \\ Chemistry, Gazi University, 06500 Teknikokullar-Ankara, Turkey; ${ }^{c}$ Faculty Science, Department \\ of Molecular Biology and Genetics, Bilkent University, 06800 Bilkent-Ankara, Turkey; \\ ${ }^{d}$ Department of Medical Biology, School of Medicine, Istanbul Kemerburgaz University, Bagcilar, \\ 34217, Istanbul, Turkey
}

(Received 24 November 2013; accepted 31 January 2014)

\begin{abstract}
The objective of the present study was to develop 2-hydroxypropyl methacrylate-co-polyethylene methacrylate [p(HPMA-co-PEG-MEMA)] hydrogels that are able to efficiently entrap doxorubicin for the application of loco-regional control of the cancer disease. Systemic chemotherapy provides low clinical benefit while localized chemotherapy might provide a therapeutic advantage. In this study, effects of hydrogel properties such as PEG chains length, cross-linking density, biocompatibility, drug loading efficiency, and drug release kinetics were evaluated in vitro for targeted and controlled drug delivery. In addition, the characterization of the hydrogel formulations was conducted with swelling experiments, permeability tests, Fourier transform infrared, SEM, and contact angle studies. In these drughydrogel systems, doxorubicin contains amine group that can be expected a strong Lewis acid-base interaction between drug and polar groups of PEG chains, thus the drug was released in a timely fashion with an electrostatic interaction mechanism. It was observed that doxorubicin release from the hydrogel formulations decreased when the density of cross-linking, and drug/polymer ratio were increased while an increase in the PEG chains length of the macro-monomer (i.e. PEG-MEMA) in the hydrogel system was associated with an increase in water content and doxorubicin release. The biocompatibility of the hydrogel formulations has been investigated using two measures: cytotoxicity test (using lactate dehydrogenase assay) and major serum proteins adsorption studies. Antitumor activity of the released doxorubicin was assessed using a human SNU398 human hepatocellular carcinoma cell line. It was observed that doxorubicin released from all of our hydrogel formulations which remained biologically active and had the capability to kill the tested cancer cells.
\end{abstract}

Keywords: hydrogels; biocompatibility; drug delivery; doxorubicin; hepatocellular carcinoma cell; biomedical applications

\section{Introduction}

Selective and targeted delivery of drugs is a major challenge for effective therapy of many diseases. An ideal drug delivery system should be inert, biocompatible,

*Corresponding author. Email: gbayramoglu@gazi.edu.tr 
mechanically strong, comfortable for the patient, capable of achieving a high drug loading for the required blood levels, immune to accidental release, simple to apply, and easy to fabricate.[1-5] Hydrogels are hydrophilic polymer networks which can retain large amount of water, and expand from 10 to $1000 \%$ of their dry weight. The networks change its volume by imbibing or draining water in response to environmental factors such as temperature, $\mathrm{pH}$, light, or ionic strength.[4-8] Entrapment of anticancer drugs to hydrogels is a promising approach to improve the efficacy and reduce the side effects of these drugs.[8,9] Numerous hydrogel-drug formulations have been developed for controlled release of active ingredients. Among them, poly(2-hydroxypropyl methacrylate), p(HPMA), and its copolymer hydrogels have found extensive applications in the biomedical field mainly because of their good chemical stability and high biocompatibility.[10-14] Hydrogels containing PEG are interesting biomaterials because they exhibit low degrees of protein adsorption and cell adhesion, low toxicity, and good water soloublity.[15-20]

Doxorubicin is a chemotherapeutic agent commonly used in the treatment of a wide range of different cancer types. The use of doxorubicin and its derivatives causes dilated cardiomyopathy and congestive heart failure due to the accumulation of the drug and results in doxorubicin-induced cardiotoxicity.[21,22] In addition, doxorubicin has been used as a model drug in many drug release studies, and different hydrogel formulations have been used for developing these drug release systems.[23,24] Electrostatic interactions between doxorubicin and hydrogels were previously reported for controlled release of the drug.[25,26] Hybrid hydrogel is another approach that has been used in controlled release studies.[27] For example, chitosan-gold particles or chitosan-polyvinyl alcohol conjugates were reported as drug delivery systems for controlled doxorubicin release with low toxicity to healthy tissues.[28,29]

In this study, hydrogel networks consisting of poly(2-hydroxypropyl methacrylate, and polyethylene glycole-methylether methacrylate) with different compositions and doxorubicin loading were prepared by UV-induced polymerization for the construction of a controlled drug release system. The hydrogel films were characterized by Fourier transform infrared (FTIR), SEM, swelling ratios, permeability, and contact angle studies. The effects of the PEG chain length of the macro-monomer (i.e. PEG-MEMA-1-3 ratio), cross-linker density, and the amount of loaded drug on the doxorubicin release were studied in a continuous drug release system. The kinetics of drug release from $\mathrm{p}$ (HPMA/PEG-MEMA) formulations were also analyzed. The major blood protein interactions with the hydrogel formulations were also determined. Finally, in vitro antitumor efficiency of the five different doxorubicin loaded p(HPMA/PEG-950-300)-X1 and $\mathrm{p}(\mathrm{HPMA} / \mathrm{PEG}-300)-\mathrm{X} 1-\mathrm{X} 3$ formulations were evaluated using SNU398 human hepatocellular carcinoma cell line. The results were compared with the antitumor effects of the drug free counterparts of these formulations under the same conditions. To this end, the aim of this study was to determine optimum PEG chain length and the amount of cross-linker.

\section{Materials and methods}

\subsection{Materials}

2-Hydroxypropyl methacrylate (HPMA), polyethylene glycole-methylether methacrylate (PEG-MEMA) with three different average Mn 300, 475, and 975 (i.e. PEG chains length), N,N-methylene bisacrylamide (BisAA), tetramethylene diamine (TEMED), and ammonium persulphate (APS) were obtained from Sigma-Aldrich chemicals $\mathrm{GmbH}$ 
(Germany). Human serum albumin (HSA), human immuno-globulins (Igs), and fibrinogen were supplied from Sigma-Aldrich and used as received. Doxorubicin was supplied by Fresenius Ltd., UK and used as received. Its chemical formula is shown in Figure 1(a). All other chemicals were of reagent grade and were purchased from Merck AG (Darmstadt, Germany). All other chemicals were analytical-grade and were purchased from Merck AG (Darmstadt, Germany).

\subsection{Cell culture}

SNU398 Human hepatocellular carcinoma cell line was cultured in RPMI medium (LONZA) supplemented with $10.0 \%$ fetal bovine serum, $1.0 \%$ non-essential amino acids, and $1.0 \%$ Penicillin/Streptomycin antibiotic at $37^{\circ} \mathrm{C}$ in $5.0 \% \mathrm{CO}_{2}$ incubator.

\subsection{Preparation of the $\mathrm{p}(\mathrm{HPMA} / \mathrm{PEG}-\mathrm{MEMA})$ hydrogel film formulations}

The $\mathrm{p}$ (HPMA/PEG-MEMA) hydrogel film formulations were prepared using UV-induced polymerization process. The representative chemical structure of the copolymer film is presented in Figure 1(b). To test the effects of PEG chains length on the drug entrapment efficiency and release rates, PEG-MEMA macro-monomers with three different averages Mn (i.e. 950, 475, and 300) were used in the initial polymerization mixture, and here after the formulations were referred to p(HPMA/PEG-950)X1, $\mathrm{p}(\mathrm{HPMA} / \mathrm{PEG}-475) \mathrm{X} 1$, and $\mathrm{p}(\mathrm{HPMA} / \mathrm{PEG}-300) \mathrm{X} 1$, respectively. The monomer (2-hydroxypropyl methacrylate; $0.75 \mathrm{~mL}$ ), macro-monomer (polyethylene glycole-methylether methacrylate, $0.75 \mathrm{~mL}$ ), cross-linker (i.e. N,N-methylene-bisacrylamide; $1.0 \mathrm{mg}$, it was donated by $\mathrm{X})$, amonium persulphate $(5.0 \mathrm{mg})$, TEMED $(10 \mu \mathrm{L}$ from $10 \%$ solution $\mathrm{w} / \mathrm{v})$, and absolute ethanol $(0.5 \mathrm{~mL})$ were transferred in phosphate buffer $(1.0 \mathrm{~mL}$, $50 \mathrm{mM}, \mathrm{pH}$ 7.0) (Table 1). To check the effects of the cross-linker density on the film properties and drug release efficiency in the initial polymerization mixture, the amount of added BisAA was varied between 1.0 and $3.0 \mathrm{mg}$ (or 6.5 and $19.2 \mu \mathrm{mol}$ ), and the same amount macro-monomer PEG-MEMA-300 was used as described above. Here

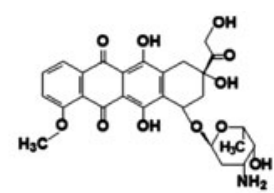

(a)

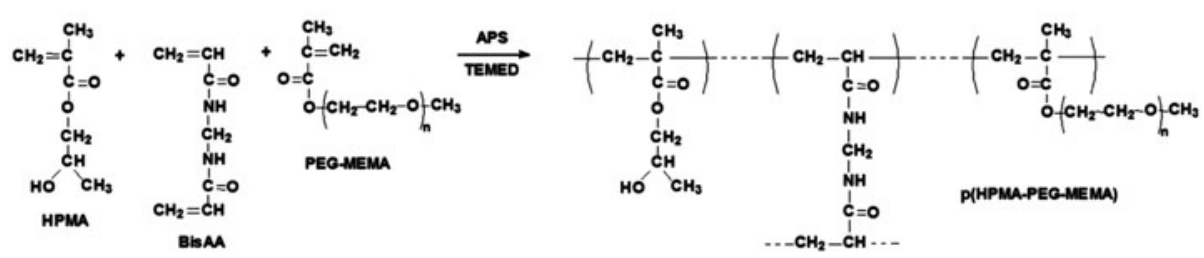

(b)

Figure 1. (a) Chemical formula of doxorubicin; (b) Chemistry of p(HPMA/PEG-MEMA) hydrogels. 
after, the formulations were referred as $\mathrm{p}(\mathrm{HPMA} / \mathrm{PEG}-300) \mathrm{X} 1 \mathrm{p}(\mathrm{HPMA} / \mathrm{PEG}-300) \mathrm{X} 2$ $\mathrm{p}(\mathrm{HPMA} / \mathrm{PEG}-300) \mathrm{X} 3$. These resulting mixtures were equilibrated at $4{ }^{\circ} \mathrm{C}$ for $30 \mathrm{~min}$ in a thermostatic water bath. Each polymerization mixture was transferred in a flat glass mold (internal diameter: $6.5 \mathrm{~cm}$ ). After sealing, a nitrogen atmosphere was created by purging nitrogen gas for $5 \mathrm{~min}$. It was then exposed to UV radiation (TUW series, Philips; UV-C, 254-nm short wave, $24 \mathrm{~W}$, Ankara, Turkey) at $4{ }^{\circ} \mathrm{C}$ for $30 \mathrm{~min}$. The obtained hydrogel films were cut into disks by means of a perforator $(0.5 \mathrm{~cm}$ in diameter and about $600 \mu \mathrm{m}$ in thickness), and stored at $4{ }^{\circ} \mathrm{C}$ in the same buffer until use. For the preparation of drug-loaded formulations, doxorubicin in two different concentrations, 0.5 and $1.0 \mathrm{mg} / \mathrm{mL}$, were added to the polymerization mixture (Table 1).

\subsection{Characterization studies of the hydrogel films}

The densities of the five different $\mathrm{p}$ (HPMA/PEG-950-300)X1, and p(HPMA/PEG-300) $\mathrm{X} 1-\mathrm{X} 3$, formulations were determined by Gay-Lussac pycnometer (Dahlewitz, Germany), and n-decane was chosen as the inert liquid, which is a non-solvent for the hydrogel. The thickness of the hydrogel films was estimated by a micrometer thickness gage. The morphology of hydrogel films and its drug-loaded counterpart were investigated by a JEOL (Tokyo, Japan) model JSM 5600 scanning electron microscope. The dried polymer films were mounted on the base plate and then coated with gold in vacuum. The morphology and surface structure of the films were obtained at the required magnification at room temperature. FTIR spectra of the $\mathrm{p}(\mathrm{HPMA} / \mathrm{PEG}-300) \mathrm{X} 1$ films were obtained by an FTIR spectrophotometer (FTIR 8000 series, Shimadzu, Tokyo, Japan). The dry sample (ca. $0.01 \mathrm{~g}$ ) was mixed with $\mathrm{KBr}(0.1 \mathrm{~g})$ and pressed into tablet form.

\subsection{Determination of volume fraction of water in hydrogels}

The water contents of the p(HPMA/PEG-950-300)X1, and p(HPMA/PEG-300)X1-X3 hydrogels were determined by swelling measurements at $37^{\circ} \mathrm{C}$. The samples $(0.1 \mathrm{~g})$ were first immersed in physiological phosphate buffer solution (PBS) $\mathrm{pH} 7.4,50 \mathrm{mM}$, containing $0.85 \% \mathrm{NaCl}$. The immersion time was $24 \mathrm{~h}$. The films were removed from PBS and their wet weights were determined after first blotting with a filter paper to remove surface absorbed PBS. The water content was calculated by the following equation:

$$
\text { Water content }=\left[\left(W_{s}-W_{d}\right) / W_{s}\right]
$$

Table 1. Formulation of p(HPMA/PEG-950-300)X1 and p(HPMA/PEG-300)X1-X3 hydrogels, density, water content, permeability, and drug loading efficiency to doxorubicin.

\begin{tabular}{|c|c|c|c|c|c|c|}
\hline $\begin{array}{l}\text { Hydrogel } \\
\text { formulations }\end{array}$ & $\begin{array}{c}\text { Monomer ratio } \\
\text { HPMA/PEG- } \\
\text { MEMA } \\
\text { (mmoL/mmoL) }\end{array}$ & $\begin{array}{l}\text { Cross- } \\
\text { linker } \\
(\mu \mathrm{moL})\end{array}$ & $\begin{array}{l}\text { Density } \\
\left(\mathrm{g} / \mathrm{cm}^{3}\right)\end{array}$ & $\begin{array}{l}\text { Water } \\
\text { content } \\
(\%)\end{array}$ & $\begin{array}{l}\text { Permeability } \\
\text { to doxorubicin } \\
\left(\mathrm{cm}^{2} / \mathrm{s} \times 10^{-9}\right)\end{array}$ & $\begin{array}{c}\text { Drug } \\
\text { loading } \\
\text { efficiency } \\
(\%)\end{array}$ \\
\hline p(HPMA/PEG-950)X1 & $5.55 / 0.80$ & 6.5 & 1.036 & $579 \pm 22$ & $91.36 \pm 2.21$ & $75.4 \pm 3.7$ \\
\hline p(HPMA/PEG-475)X1 & $5.55 / 1.71$ & 6.5 & 1.089 & $433 \pm 24$ & $79.64 \pm 2.42$ & $79.8 \pm 2.5$ \\
\hline p(HPMA/PEG-300)X1 & $5.55 / 2.63$ & 6.5 & 1.103 & $171 \pm 18$ & $32.83 \pm 1.14$ & $84.0 \pm 3.7$ \\
\hline $\mathrm{p}(\mathrm{HPMA} / \mathrm{PEG}-300) \mathrm{X} 2$ & $5.55 / 2.63$ & 12.7 & 1.158 & $107 \pm 06$ & $19.81 \pm 1.22$ & $87.9 \pm 2.6$ \\
\hline p(HPMA/PEG-300)X3 & $5.55 / 2.63$ & 19.2 & 1.176 & $77 \pm 03$ & $12.35 \pm 0.17$ & $89.2 \pm 1.4$ \\
\hline
\end{tabular}


where $W_{d}$ and $W_{s}$ are the weights of the samples in the dry and swollen states, respectively. Each swelling experiment was repeated three times and the average value was reported.

\subsection{Determination of permeability of hydrogel formulations}

All permeability tests were performed at $25^{\circ} \mathrm{C}$, using a diffusion cell which had two cylindrical compartments $(160 \mathrm{~mL}$ volume $)$ and a connecting film holder $(2.0 \mathrm{~cm}$ i.d.). The donor compartment was filled with an aqueous doxorubicin solution in physiological phosphate buffer solution (PBS; $\mathrm{pH} 7.4,10 \mathrm{mM}, 0.85 \% \mathrm{NaCl}$ ). The acceptor compartment was filled with PBS, and stirred magnetically. Through the acceptor chamber, the same buffer solution was pumped at a rate of $20 \mathrm{~mL} / \mathrm{h}$ in a single-pass manner and the effluent was collected by means of a fraction collector. The permeation was continued for $24 \mathrm{~h}$, and the collected samples were assayed spectrophotometrically for doxorubicin at $490 \mathrm{~nm}$. Each permeation experiment was repeated three times and the permeability of doxorubicin $(P)$ from various film formulations were calculated using the following equation:

$$
\ln C_{t} / C_{0}=P S t / v h
$$

where $P$ is the permeability of film $\left(\mathrm{cm}^{2} / \mathrm{s}\right) ; C_{t}$ and $C_{0}$ are the concentration of doxorubicin in the donor compartment at time $t$ and $t_{0}$, respectively; $S$ is the film area of the holder $\left(\mathrm{cm}^{2}\right) ; t$ is time $(\mathrm{s}) ; v$ is the volume of donor compartment $(\mathrm{mL})$, and $\mathrm{h}$ is the film thickness $(\mathrm{cm}) . C_{t}$ was calculated from the difference of $C_{0}$, and the amount of collected in the acceptor compartment. The slope of $\ln C_{t} / C_{0}$ vs. $P S / v h$ yielded permeability.

\subsection{Contact angle studies}

Contact angles to water, glycerol, and dimethyl sulfoxide of p(HPMA/PEG-950)X1, p(HPMA/PEG-475)X1，p(HPMA/PEG-300)X1，p(HPMA/PEG-300)X2，and p(HPMA/ PEG-300)X3, formulations were measured by sessile drop method at $25^{\circ} \mathrm{C}$ by using a digital optical contact angle meter Phoneix 150 (Surface Electro Optics, Korea). The sessile drop was formed by depositing the liquid from the above using a manual microsyringe on the membrane surfaces. Both the left and right contact angles and drop dimension parameters were automatically calculated from the digitalized image. The measurements were the average of five contact angles at least operated on three membrane samples.

\subsection{Interaction of major serum proteins with the hydrogel films}

To determine the antifouling properties of the p(HPMA/PEG-950-300)X1, and $\mathrm{p}$ (HPMA/PEG-300)X1-X3, formulations, the adsorption of human serum albumin (HSA), human immuno-globulins (HIg), and fibrinogen was studied at $37^{\circ} \mathrm{C}$ for $18 \mathrm{~h}$ in a batch system. The initial concentration of each protein was $0.5 \mathrm{mg} / \mathrm{mL}$ in the individual adsorption medium. The amount of adsorbed protein on the film surface was obtained by the following equation:

$$
q=\left[\left(C_{0}-C\right) V\right] / S
$$


where $q$ is the amount of protein adsorbed onto the film surface $\left(\mu \mathrm{g} / \mathrm{cm}^{2}\right) ; C_{0}$ and $C$ are the concentrations of protein in the solution before and after adsorption, respectively $(\mathrm{mg} / \mathrm{mL}) ; V$ is the volume of the protein solution; and $S$ is the surface area of the film.

The amounts of protein adsorbed onto the five different p(HPMA/PEG-950-300)X1, and p(HPMA/PEG-300)X1-X3 films, were determined using Coomassie Brilliant Blue as described by Bradford [30]. Calibration curves were prepared from HSA, HIgs, and fibrinogen and used in the calculation of the protein content of the solutions $(0.02-0.2 \mathrm{mg} / \mathrm{mL})$.

\subsection{In vitro cytotoxicity studies of hydrogel films}

The lactate dehydrogenase (LDH) is a cytoplasmic enzyme. Normally, it is not secreted outside the cells, but upon damage of cell membrane LDH leaks out. With LDH test, it is possible to measure the release of $\mathrm{LDH}$ from cells based on a colorimetric quantitation after an enzymatic reaction. This assay measures the LDH activity in the cell culture supernatants. LDH leakage was measured from cells by LDH Cytotoxicity Detection Kit (Clontech $\left.{ }^{\circledR}\right)$. Non-Radioactive Cytotoxicity assay was performed following the manufacturer's protocol. Human hepatocellular carcinoma (SNU398) cell line was used to evaluate the cytotoxicity of the hydrogel formulations. The hydrogel formulations (i.e. p(HPMA/PEG-950)X1, p(HPMA/PEG-475)X1, p(HPMA/PEG-300)X1, p(HPMA/PEG-300)X2, and p(HPMA/PEG-300)X3), and their doxorubicin loaded counterparts were placed in 96-well plates in triplicates. $2 \times 10^{4}$ SNU398 cells were cultured on each well in $200 \mu \mathrm{L}$ medium. LDH Cytotoxicity Detection Kit (Clontech $\left.{ }^{\circledR}\right)$ was used to measure the cytotoxicity and the effects of these formulations were calculated according to the manufacturer's protocols. The readings were performed by using an ELISA reader at the wavelength value of $490 \mathrm{~nm}$. Each experiment was repeated at least three times.

\subsection{Antitumor activity of doxorubicin loaded hydrogel formulations}

The five different p(HPMA/PEG-950-300)X1, and p(HPMA/PEG-300)X1-X3 hydrogel formulations and their Doxorubicin loaded counterparts were placed in 24-well plates in triplicates. $3 \times 10^{4}$ SNU398 cells were cultured on each well in $1.0 \mathrm{~mL}$ medium. Control group with $3 \times 10^{4}$ cells cultured directly on bare plate surface without any hydrogel was also included. The medium was changed at the third date and cell counting was performed at the sixth date with a hemocytometer after trypsinization. For the statistical analysis, Minitab ${ }^{\circledR}$ program was used. Fisher test was done with $95 \%$ confidential interval value.

\subsection{Determination of doxorubicin content of the hydrogel formulations}

A sample was weighed (about $0.1 \mathrm{~g}$ ) and was transferred in $10 \mathrm{~mL}$ of methanol. It was incubated at $25^{\circ} \mathrm{C}$ for $24 \mathrm{~h}$ to elute doxorubicin. The efficiency of the drug-loaded hydrogel formulations was calculated by the following equation:

Loading efficiency $(\%)=$ (Amount of drug in drug loaded hydrogel/

Total amount of drug used in the preparation of drug loaded hydrogel)

$$
\times 100 \%
$$

The drug concentration in the elution was measured as described above. 


\subsection{Controlled release studies of doxorubicin from the hydrogel film formulations}

The in vitro release studies were conducted in a continuous flow system with constant stirring. Doxorubicin loaded five different hydrogel formulations $(0.5 \mathrm{~g})$, were placed in the continuous flow drug release cell, and a physiological buffer solution ( $\mathrm{pH} 7.4)$ was introduced through the bottom inlet port of the flow cell at a flow rate of $10 \mathrm{~mL} / \mathrm{h}$ at $37^{\circ} \mathrm{C}$ with a peristaltic pump (model IPC, Ismatec, Düsseldorf, Germany). The effluent was collected at predetermined time intervals, and the released doxorubicin (at a maximum wavelength of $490 \mathrm{~nm}$ ) was determined spectrophotometrically (model 1601, Shimadzu). The analyzed solution was added back to the collected dissolution media to maintain a constant volume. To study the effect of the doxorubicin loading on the release rate, similar procedures were followed for 0.5 and $1.0 \mathrm{mg} / \mathrm{mL}$ drug-loaded samples. All experiments were repeated three times to minimize the error variation. Therefore, the data presented in the graphs show the average values of three experiments. The model drug concentration in the collected dissolution medium was calculated with a calibration curve obtained from samples of known concentrations.

\section{Results and discussions}

\subsection{Characterization of hydrogel films}

The surface properties and swelling characteristics of hydrogels are critical in tissue engineering applications, as it correlates with the diffusivity of oxygen, drugs, nutrients, and other water-soluble metabolites. The swelling behaviors of the p(HPMA/PEG-950) X1， p(HPMA/PEG-475)X1， p(HPMA/PEG-300)X1， p(HPMA/PEG-300)X2, and $\mathrm{p}(\mathrm{HPMA} / \mathrm{PEG}-300) \mathrm{X} 3$ hydrogels were investigated over a period of $24 \mathrm{~h}$ in PBS at $37^{\circ} \mathrm{C}$ (Figure 2). The codes $300-950$ and $\mathrm{X} 1-\mathrm{X} 3$ were assigned to various hydrogels according to the difference in the PEG chains length and the amount of cross-linker used, respectively. The dynamic swelling profiles of the hydrogel formulations exhibited fast swelling behavior in the first hour and achieved the equilibrium state within $10 \mathrm{~h}$ in PBS. The initial faster swelling behavior of the copolymer hydrogels was due to the osmotic pressure difference. On the other hand, the p(HPMA/PEG-950)X1, $\mathrm{p}(\mathrm{HPMA} / \mathrm{PEG}-475) \mathrm{X} 1$, and $\mathrm{p}(\mathrm{HPMA} / \mathrm{PEG}-300) \mathrm{X} 1$ hydrogel formulations were used to study the effect of chain length on the hydrogel properties and drug release behaviors. Figure 2 shows the degree of swelling as a function of time for the hydrogel formulations based on variable PEG chain length. The general trend for the tested formulations is an increased swelling degree with increasing PEG chain length (Table 1). Thus, the increase of PEG chain length in the HPMA/PEG hydrogel systems altered the bulk properties of the resulting gels. The PEG chains of PEG-MEMA were expected to be spread over the gel surface because the pendant PEG components were more hydrophilic than the copolymer backbone, as evidenced by the swelling behavior and contact angle data (Tables 1 and 2). The effect of the cross-linker content on the swelling ratio for the p(HPMA/PEG-300)X1, p(HPMA/PEG-300)X2, and p(HPMA/ PEG-300)X3 hydrogel formulations in Table 1 indicates that the swelling ratios for these gels increase in the order of $p($ HPMA/PEG-300)X1 $>p($ HPMA/PEG-300)X2 $>p$ (HPMA/PEG-300)X3. In these experiments, the cross-linker concentrations (i.e. Bis AA) were $6.5,12.7$, and $19.2 \mu \mathrm{moL}$. As the amount of cross-linker increases in the hydrogel, the cross-linking density increases leading to the development of higher elastic constraint when the gels are swelled in water (Table 1). This result implies that the structure of the gels would become denser and more tightened as the amount of 

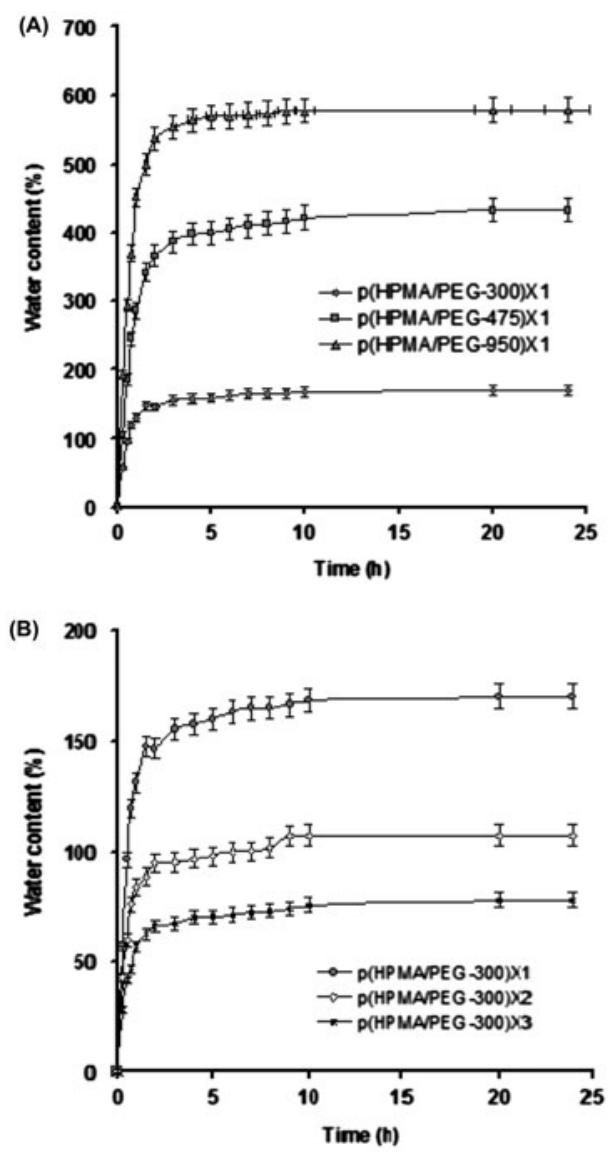

Figure 2. The swelling behavior: (A) p(HPMA/PEG-950)X1, p(HPMA/PEG-475)X1, and p(HPMA/PEG-300)X1; (B) p(HPMA/PEG-300)X1， p(HPMA/PEG-300)X2， and p(HPMA/ PEG-300)X3, hydrogels in PBS at $37^{\circ} \mathrm{C}$. (Each swelling experiment was repeated three times, and the $p$-value $>0.05$ was used in the statistical analysis.)

cross-linker increased and this would decrease the space between gel networks and result in a decrease in the swelling ratio. Hence, higher the extent of BisAA in the gel, swelling ratio becomes lower as expected. For the hyrogels containing the smallest amount of cross-linker, $6.5 \mu \mathrm{moL}$, the swelling percentage is about $171 \%$ at swelling equilibrium. For the gel containing the highest amount of cross-linker, $19.2 \mu \mathrm{moL}$, the swelling percentage is about $77 \%$ at swelling equilibrium. In these hydrogel systems, both of the monomers (i.e. HPMA and PEG-MEMA) were hydrophilic in nature and thus permit large intake of water by the cross-linked gel network; even though the cross-linker is less flexible and less hydrophilic.

The FTIR spectra of p(HPMA/PEG-300)X1 and its doxorubicin loaded counterpart had the characteristic stretching vibration band of hydrogen-bonded alcohol $(-\mathrm{OH})$ around $3430 \mathrm{~cm}^{-1}$, and the $\mathrm{C}=\mathrm{O}$ stretching vibration of the ester group also appeared at $1719 \mathrm{~cm}^{-1}$ (Figure 3). On the other hand, several bands appeared in the fingerprint region for PEG between 1600 and $1200 \mathrm{~cm}^{-1}$ on the p(HPMA/PEG-300)X1 structures. These peaks were 
Table 2. Contact angle values of the p(HPMA), p(HPMA/PEG-950-300)X1, and p(HPMA/PEG-300)X1-X3 hydrogel formulations using water, glycerol, and dimethyl sulfoxide.

\begin{tabular}{lccc}
\hline & Water & Glycerol & Dimethyl sulfoxide \\
\hline p(HPMA) & $70.1 \pm 3.8$ & $72.3 \pm 3.1$ & $35.7 \pm 1.4$ \\
p(HPMA/PEG-950)X1 & $43.4 \pm 0.9$ & $49.8 \pm 1.7$ & $36.1 \pm 1.4$ \\
p(HPMA/PEG-475)X1 & $50.2 \pm 1.3$ & $55.7 \pm 2.4$ & $33.6 \pm 0.8$ \\
p(HPMA/PEG-300)X1 & $57.8 \pm 1.2$ & $62.7 \pm 1.9$ & $32.7 \pm 1.1$ \\
p(HPMA/PEG-300)X2 & $54.7 \pm 2.4$ & $58.2 \pm 2.1$ & $28.3 \pm 0.6$ \\
p(HPMA/PEG-300)X3 & $48.9 \pm 1.6$ & $51.5 \pm 2.2$ & $24.7 \pm 0.9$ \\
\hline
\end{tabular}

assigned to the $-\mathrm{CH}_{2}$ scissoring band of PEG at $1453 \mathrm{~cm}^{-1}$ and the antisymmetric and symmetric stretching bands $\left(-\mathrm{OCH}_{2}-\mathrm{CH}_{2}\right)$ of PEG at 1371 and $1248 \mathrm{~cm}^{-1}$, respectively. The spectra mark the presence of doxorubicin as evident from the observed bands at 1000 $1260 \mathrm{~cm}^{-1}$ (C-O stretching of alcohol) and $675-900 \mathrm{~cm}^{-1}$ (out of plane $\mathrm{O}-\mathrm{H}$ bending).

Figure 4(A) and (B) shows scanning electron micrographs of the p(HPMA) and p(HPMA/PEG-300)X1 hydrogels, respectively. The SEM micrograph of the p(HPMA) hydrogel surface showed a porous structure (Figure 4(A)). For the surface of p(HPMA/ PEG-300)X1 hydrogel networks, PEG chains were incorporated with the co-monomer PEG-MEMA, exhibited a non-porous and smooth structure compared to the surface of p(HPMA) (Figure 4(B)). A detailed examination of the SEM figure showed that the pores had a view of either filled or closed with PEG chains and had a much smoother surface structure compared to $\mathrm{p}$ (HPMA) hydrogel surfaces.

\subsection{Contact angle data of hydrogel films}

The PEG brushes is of significant importance as the peculiar physicochemical properties of PEG afford surfaces with interesting non-biofouling properties such as resistance to protein adsorption or cells adhesion are obtained. These parameters are critically important for the development of biomaterials in the field of tissue engineering and regenerative medicine. Therefore, contact angle measurements are used in the characterization of material surfaces to describe the hydrophilicity. The wettability of biomaterial surfaces can be examined by comparing the contact angles for water and diiodomethane; since these two solvents are often used as reference liquids in analyses of interaction of polar and apolar solvents with solid surfaces. The results of the contact angle measurements of water, glycerol, and dimethyl sulfoxide on the p(HPMA), p(HPMA/PEG-950)X1, p(HPMA/PEG-475)X1, p(HPMA/PEG-300)X1, p(HPMA/PEG-300)X2, and p(HPMA/ PEG-300)X3, hydrogels surfaces are presented in Table 2. It can be seen that all the composite hydrogels (i.e. PEG carrying hydrogels) showed lower water contact angles than those of the pure $\mathrm{p}$ (HPMA). All the investigated samples yielded a different contact angle value, and all the tested hydrogel compositions had polar surfaces. As seen in Table 2, as the PEG chains length increased in the macro-monomer structure, the water contact angles decreased. It should also be noted that, the molar ratio of the macro-monomer with larger PEG chains was lower than that of the macro-monomer with smaller PEG chains (Table 2), since the PEG carrying macro-monomer ratio was maintained at $50 \%$ in each hydrogel formulation. This suggests that the hydrogel containing the macro-monomer with high PEG chain length should have the highest surface density because it contains the lowest methylether methacrylate (MEMA) units of the heterofunctional polymer backbone chains. Thus, the contact angle value of the 


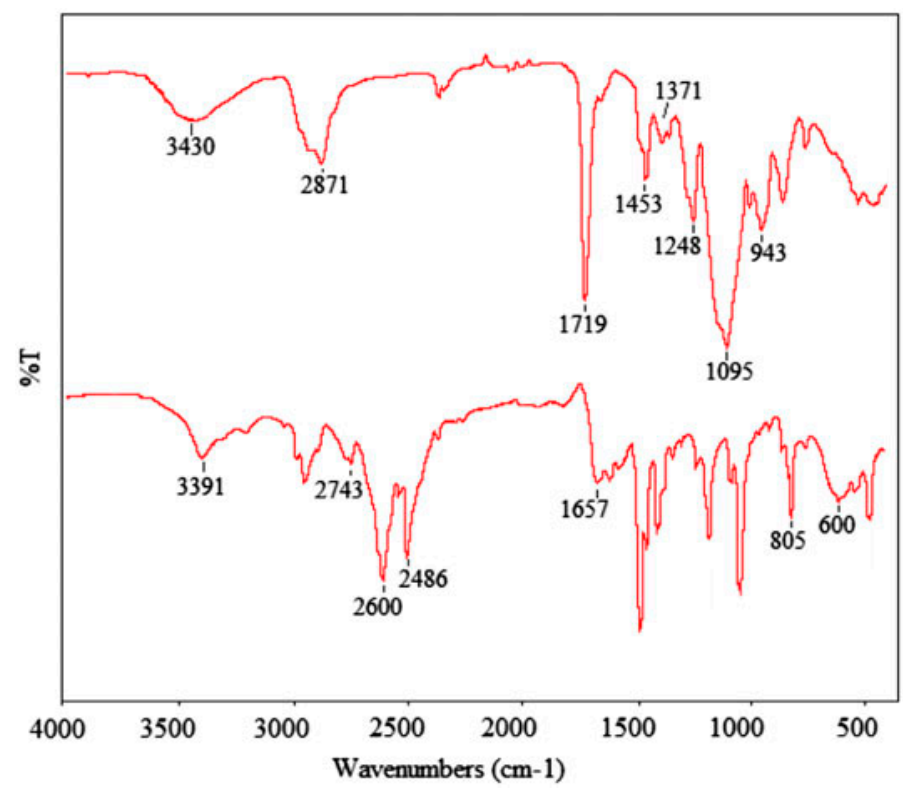

Figure 3. The FTIR spectra of p(HPMA/PEG-300)X1 and its doxorubicin loaded counterpart.
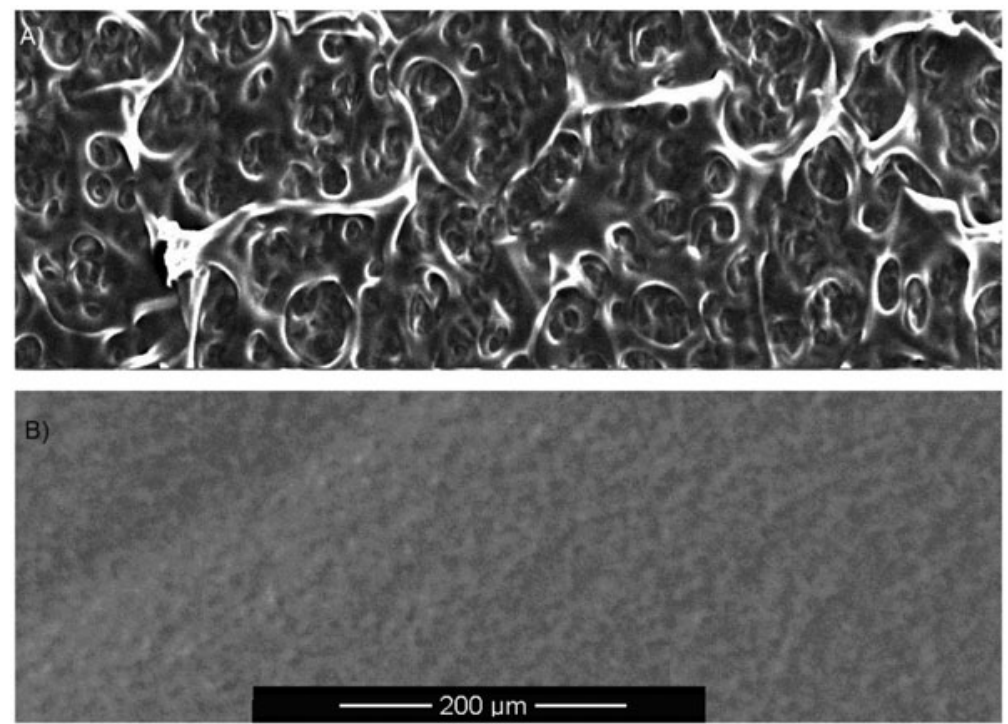

Figure 4. Scanning electron micrographs of (A) the p(HPMA) and (B) p(HPMA/PEG-300)X1 hydrogels.

hydrogels decreased with increasing PEG chain length in the macro-monomer structure, as indicated by an increase in the swelling ratio of the copolymer hydrogel. On the other hand, the relatively high contact angles was observed with the hydrogels containing 
lower molecular weight PEG-MEMA macro-monomer can be due to an incomplete coverage of the uppermost surface by PEG chains. This data highlights the importance of the incorporation of PEG-MEMA macro-monomer with varying PEG chain length in the co-monomer structure. A similar trend of reduced contact angle values with increasing PEG molecular weight was also observed in other studies.[31-33]

\subsection{Effect of hydrogel composition on the permeability}

Permeation studies were carried out in vertical type chambers with a volume of 160 $\mathrm{mL}$ in the donor and acceptor chamber and a permeation area of $3.14 \mathrm{~cm}^{2}$. All perme-

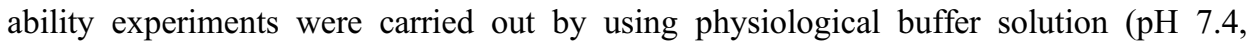
$10 \mathrm{mM}, 0.85 \% \mathrm{NaCl})$ at $25^{\circ} \mathrm{C}$. The relationship between the PEG chains length and cross-linker density on the permeability of hydrogel formulation values was studied by varying the PEG chains length of macro-monomer and BissAA concentration in the polymerization mixture (Table 1). It was observed that the permeability to doxorubicin was substantially increased when the PEG chains length was increased in the hydrogel formulations (Table 1). The increment in the permeability values of the hydrogels can be attributed to the higher hydrophilicity of the PEG and the greater availability of PEG molecules in the structure of polymer as the chains length increases. As seen in Table 1, the p(HPMA/PEG-950)X1 formulation had the highest PEG chains length which had a substantially higher water content and a higher permeability to doxorubicin $\left(91.36 \mathrm{~cm}^{2} \mathrm{~s}^{-1}\right)$. The location of the PEG had a substantial effect on the swelling and also permeability. When the PEG chains length increased in the hydrogel films, the permeability to doxorubicin increased. PEG chains remained in the bulk gel product, due to its high content of polar functional groups and large size. Additionally, the increase in the PEG chains length of macro-monomer resulted in the formation of loose networks, and the absorption of large quantities of water. This makes the hydrogel films more permeable to doxorubicin.

In order to study the influence of the cross-linking density on the doxorubicin permeability of hydrogels, formulations were prepared by changing the molar content of the cross-linking agent BisAA. Table 1 shows the permeability data of hydrogel formulations with three different cross-linker densities. It is clear that doxorubicin permeability was significantly hindered as the hydrogel cross-linking density was increased. An increase in the molar concentration of the cross-linking agent BisAA decreased the molecular weight polymer chains between cross-links, which in turn resulted in a smaller network mesh size. Doxorubicin permeability from hydrogel containing $19.2 \mu$ mole of BisAA was more obstructed and consequently slower than that of the hydrogel synthesized with $6.5 \mu$ mole of BisAA (Table 1). Hence, the increasing chains length of PEG in the hydrogel networks resulted in an increase in the drug permeability, whereas the declined effect of cross-linker was significantly higher when the amount of BisAA increased due to the decrease mesh size of the polymer networks.

\subsection{Protein adsorption studies}

One of the objectives in this study was to investigate the effects of the variations in PEG chain length and cross-linker density on surface properties of the hydrogel films. Biochemical insight into the behavior of tethered PEG under biological conditions was 
gained through assays on protein adsorption and cellular attachment experiments to a hydrophilic PEG layer. For these purposes, p(HPMA/PEG-MEMA)-X1 with different lengths of PEG and with different ratios of cross-linker density were synthesized (Table 1). The biomolecules interaction properties of $\mathrm{p}(\mathrm{HPMA} / \mathrm{PEG}-950-300) \mathrm{X} 1$, and $\mathrm{p}$ (HPMA/PEG-300)-X1-X3, were tested with three important plasma proteins (i.e. serum albumin, fibrinogen, and immunoglobulins) in a batch-wise manner. Single protein solutions of HSA albumin $(67 \mathrm{kD})$, fibrinogen $(340 \mathrm{kD})$, and Igs $(150-170 \mathrm{kD})$ in physiological buffer solution $(\mathrm{pH} 7.4)$ at a concentration of $0.5 \mathrm{mg} / \mathrm{mL}$ were then exposed to the six different surfaces for a period of $12 \mathrm{~h}$ at $37^{\circ} \mathrm{C}$, using a previously described procedure.[34] The tested proteins reached their maximum adsorption values on hydrogel formulations in about $8.0 \mathrm{~h}$ and remained constant after this period. The amounts of adsorbed HSA, fibrinogen, and Igs on the hydrogel surface are presented in Table 3. The isoelectric points of the albumin, fibrinogen, and Igs were 4.0,6.0, and 6.2 , respectively, and therefore, these proteins carried negative charges at a blood $\mathrm{pH}$ of 7.4. It should be noted that all PEG-modified surfaces showed significant decrease in HSA, fibrinogen, and immunoglobulins adsorption compared to the control surface (i.e. p(HPMA)). The relatively high basic component of the PEG-carrying hydrogel films could create a repulsive force against the negatively charged blood proteins. For example, the adsorption of all the tested proteins was significantly increased when the PEG MW was reduced from 950 to 300 (Table 3). Protein adsorption was lowest on the surfaces with the highest PEG chains surface density. Thus, p(HPMA/PEG-950)X1 surface reduced protein adsorption from 1.14 to $0.46 \mu \mathrm{g} / \mathrm{cm}^{2}$ for HSA, from 1.89 to $0.53 \mu \mathrm{g} / \mathrm{cm}^{2}$ for fibrinogen, and 1.36 to $0.67 \mu \mathrm{g} / \mathrm{cm}^{2}$ for Igs at $0.5 \mathrm{mg} / \mathrm{mL}$ individual tested protein concentration. The amounts of adsorbed HSA were significantly lower on all the tested hydrogels surfaces compared to fibrinogen and Igs. Adsorption of these proteins on the hydrogel formulations was found to be further increased by increasing the cross-linker ratio in the hydrogel structure. The highest proteins adsorption was found on $\mathrm{p}(\mathrm{HPMA} / \mathrm{PEG}-300)-\mathrm{X} 3$ surface. Thus, an increase in the chains length of PEG-MEMA macro-monomer was found to improve the antifouling properties of the materials. On the other hand, as shown in Table 3, the amounts of albumin, fibrinogen, and Igs adsorbed onto hydrogels were increased as the cross-linking density increased. The reduction in the adsorbed protein amounts can be mainly due to the reduction of water content on the surface of the hydrogels. In this work, the hydrophilic PEG chains should have been moved from the interior to the surface of the materials because the material bulk should have been less hydrophilic than that of the aqueous surroundings, so all PEG introduced into the films showed good antifouling surface properties. These results were in good agreement with the previous related literature.[35-37]

Table 3. HSA, fibrinogen, and Igs adsorption on control p(HPMA), p(HPMA/PEG-950-300)X1, and $\mathrm{p}(\mathrm{HPMA} / \mathrm{PEG}-300) \mathrm{X} 1-\mathrm{X} 3$ hydrogel formulations, from PBS (pH 7.4) buffer.

\begin{tabular}{lccc}
\hline & HSA $\left(\mu \mathrm{g} / \mathrm{cm}^{2}\right)$ & Fibrinogen $\left(\mu \mathrm{g} / \mathrm{cm}^{2}\right)$ & Immunoglobulins $\left(\mu \mathrm{g} / \mathrm{cm}^{2}\right)$ \\
\hline P(HPMA) & $9.35 \pm 0.38$ & $11.87 \pm 0.76$ & $7.33 \pm 0.33$ \\
p(HPMA/PEG-950)X1 & $0.46 \pm 0.04$ & $0.53 \pm 0.06$ & $0.67 \pm 0.03$ \\
p(HPMA/PEG-475)X1 & $0.96 \pm 0.07$ & $1.24 \pm 0.21$ & $1.08 \pm 0.02$ \\
p(HPMA/PEG-300)X1 & $1.14 \pm 0.08$ & $1.89 \pm 0.06$ & $1.36 \pm 0.03$ \\
p(HPMA/PEG-300)X2 & $1.87 \pm 0.07$ & $2.63 \pm 0.14$ & $1.88 \pm 0.05$ \\
p(HPMA/PEG-300)X3 & $2.54 \pm 0.31$ & $3.25 \pm 0.17$ & $2.56 \pm 0.23$ \\
\hline
\end{tabular}




\subsection{In vitro doxorubicin-release studies}

\subsubsection{Effect of PEG chains length}

Hydrogels have been extensively investigated as controlled drug release systems due to their excellent physicochemical properties. Drug release from hydrogel matrices is affected by many factors, such as their swelling properties, network porosity, and the erosion of the hydrogel matrix, as well as drug-polymer interactions.[38-40] In the presented hydrogel systems, the amino groups of doxorubicin are positively charged at $\mathrm{pH}$ 7.4 , because the $\mathrm{pKa}$ value of the primary amine in the sugar moiety of doxorubicin is 8.25, and the Lewis acid groups $\left(\gamma^{-}\right)$of the PEG molecules have partially negative charge. Thus, polymer and drug can interact electrostatically at $\mathrm{pH}$ 7.4. The results for the doxorubicin loading efficiency of the hydrogel formulation are presented in Table 1. The entrapment efficiency (\%) of a drug depended on the type of matrix material, entrapment method of the drug, and the polymer networks preparation conditions. As seen in this table, the drug-loading efficiency of the hydrogel film formulations depended on the PEG chain length and cross-linker density of the formulations. The entrapment efficiency decreased from 84 to $75 \%$ when the PEG chain length in the macro-monomer was increased from 300 to $975 \mathrm{Mn}$. Additionally, as the cross-linker density increased, the doxorubicin loading efficiency in the hydrogel formulation increased. The effect of the PEG chains length of the macro-monomer on the doxorubicin release kinetics for the $\mathrm{p}(\mathrm{HPMA} / \mathrm{PEG}-950-300) \mathrm{X} 1$, formulations are presented in Figure 5. The release profiles indicate that the amount of doxorubicin released increased when the PEG chain length of the hydrogel increased. The p(HPMA/PEG300)X1 hydrogel films showed $60.3 \%$ release, whereas the p(HPMA/PEG-475)X1 and p(HPMA/PEG-950)X1 hydrogel films showed 85.4 and $98.3 \%$ release, respectively, at $37^{\circ} \mathrm{C}$ and $480 \mathrm{~min}$ with $1.0 \mathrm{mg} / \mathrm{mL}$ doxorubicin loading (Figure 5(B)). These results can be explained by the more hydrophilic nature of the $\mathrm{p}(\mathrm{HPMA} / \mathrm{PEG}-950) \mathrm{X} 1$ hydrogel formulations (Table 1). With the chains length of the macro-monomer (i.e. PEGMEMA) increasing in the copolymer network, cumulative release from the formulation was increased. This observation was also expected because more hydrophilic PEG in the copolymer structures resulted in faster movement of the water to the surface of the drug-loaded film.[39,40] Additionally, the cumulative release of doxorubicin increased from 42.1, 54.1, and 61.3 to $60.2,85.4$, and $98.2 \%$ for $\mathrm{p}(\mathrm{HPMA} / \mathrm{PEG}-300) \mathrm{X} 1$ p(HPMA/PEG-475)X1 and p(HPMA/PEG-950)X1 hydrogel formulations, respectively, with increasing initial drug content of the formulations from 0.5 to $1.0 \mathrm{mg} / \mathrm{mL}$ in the polymerization medium. This can be explained by inclusion complex formation between doxorubicin and polymer networks during loading process, and these internal interactions at high polymer ratio may provide a force to prevent the drug molecules from releasing and resulted in low percent cumulative release.[41,42] This could not be a case for the high drug-loaded formulations where the cumulative releases were higher about $18-37 \%$ compared to low drug-loaded counterparts in the time frame of the experiment. At high loading, only a small portion of the drug could be interacted with the polymer network, and remaining drug could be freely suspended in the vicinity of the polymer networks. Thus, the high drug-loaded formulations showed high percent cumulative releases compared with the low drug-loaded counterparts.

\subsubsection{Effect of cross-linker density on release of doxorubicin}

The release profiles of doxorubicin in p(HPMA/PEG-300)X1, p(HPMA/PEG-300)X2, and $\mathrm{p}(\mathrm{HPMA} / \mathrm{PEG}-300) \mathrm{X} 3$ hydrogel formulations, cross-linked with different ratios of 

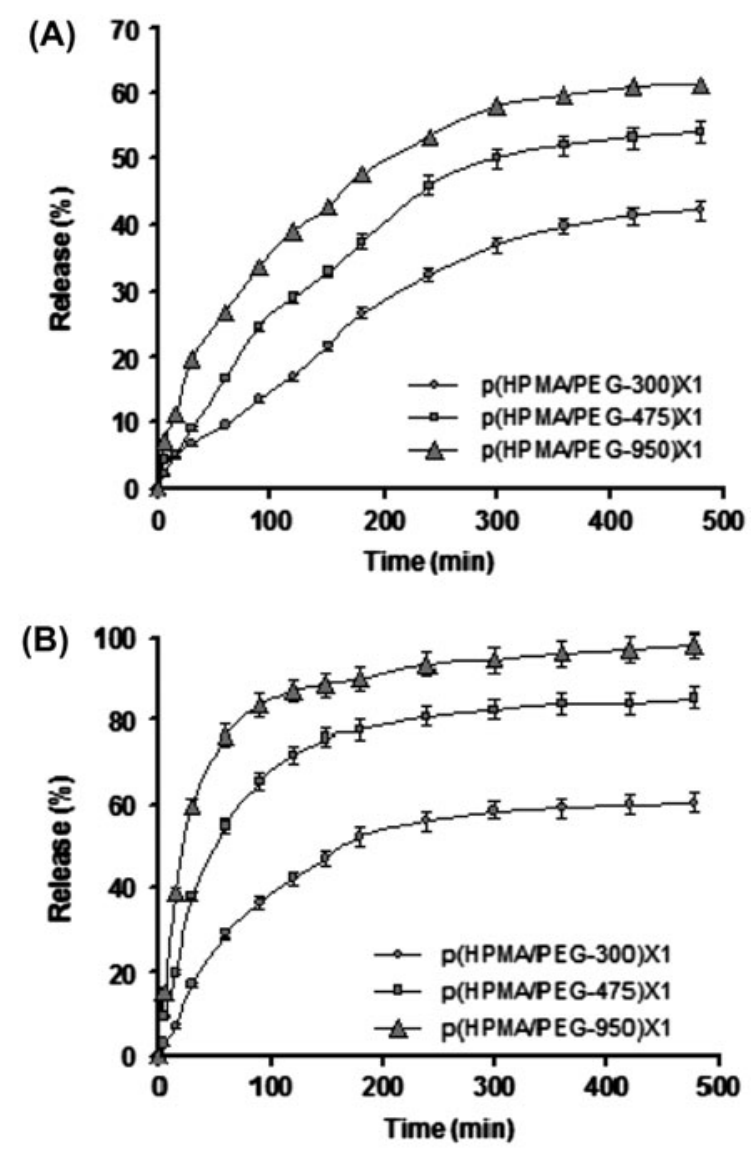

Figure 5. The effect of the PEG chains length of the macro-monomer on the doxorubicin release kinetics for the p(HPMA/PEG-300)X1, p(HPMA/PEG-475)X1, and p(HPMA/PEG-950) X1: (A) at $0.5 \mathrm{mg} / \mathrm{mL}$, and (B) at $1.0 \mathrm{mg} / \mathrm{mL}$ drug loading. (The data presented in the graphs show the average values of three experiments, and the $p$-value $>0.05$ was used in the statistical analysis.)

BisAA, are shown in Figure 6. It showed that the release rate of doxorubicin for the p(HPMA/PEG-300)X1 hydrogel formulation was higher and faster than those for the $\mathrm{p}(\mathrm{HPMA} / \mathrm{PEG}-300) \mathrm{X} 2$ and $\mathrm{p}(\mathrm{HPMA} / \mathrm{PEG}-300) \mathrm{X} 3$ formulations. This was due to the lower cross-linking density and higher swelling ratio of p(HPMA/PEG-300)X1. From this and above observations, the doxorubicin release behavior mainly depended on the swelling ratio of the hydrogel formulations. Figure 6 also presents cumulative doxorubicin release profiles for the hydrogel formulations. The p(HPMA/PEG-300)X1 hydrogel films showed $60.3 \%$ release, whereas the p(HPMA/PEG-300)X2 and p(HPMA/PEG-300)X3 hydrogel films showed 53.2 and $43.1 \%$ release, respectively, at $37^{\circ} \mathrm{C}$ and $480 \mathrm{~min}$ with $1.0 \mathrm{mg} / \mathrm{mL}$ doxorubicin loading. The initial release rate of the drug from the hydrogels was rapid, and this initial fast release may be attributed to the rapid diffusion of doxorubicin that was loaded close to the surface of the hydrogels. Later on, the drug was released more slowly from the hydrogels. 


\subsubsection{Kinetic evaluation of drug release mechanism}

The mathematical theory of diffusion for isotropic substances is based on the hypothesis that the rate of transfer of the diffusing substance through a unit of area of a section is proportional to the concentration gradient measured normal to the section (i.e. Fick's first law of diffusion). Fick's first law assumes that the concentration gradient is independent of time. However, during a real diffusion process, the concentration of the diffusing species within the host matrix is changing with the time at any given position.[43] The Fickian mechanism is often applied to diffusion-controlled release behavior because of its simple mathematics. A situation that does not conform to these conditions is described as either case II or anomalous behavior.[44]

To analyze the in vitro release data, various kinetic models were used to describe the release kinetics. The following plots were used to analyze release behaviors; (i) cumulative \% drug release vs. time (zero-order kinetic model, Equation (5)); (ii) log cumulative of $\%$ drug remaining vs. time (first-order kinetic model, Equation (6)); (iii) cumulative \% drug release vs. square root of time (Higuchi model, Equation (7)); (iv) $\log$ cumulative \% drug release vs. log time (Korsmeyer-Peppas model, Equation (8)), and (v) cube root of drug \% remaining in matrix vs. time (Hixson-Crowell cube root law, Equation (9)).
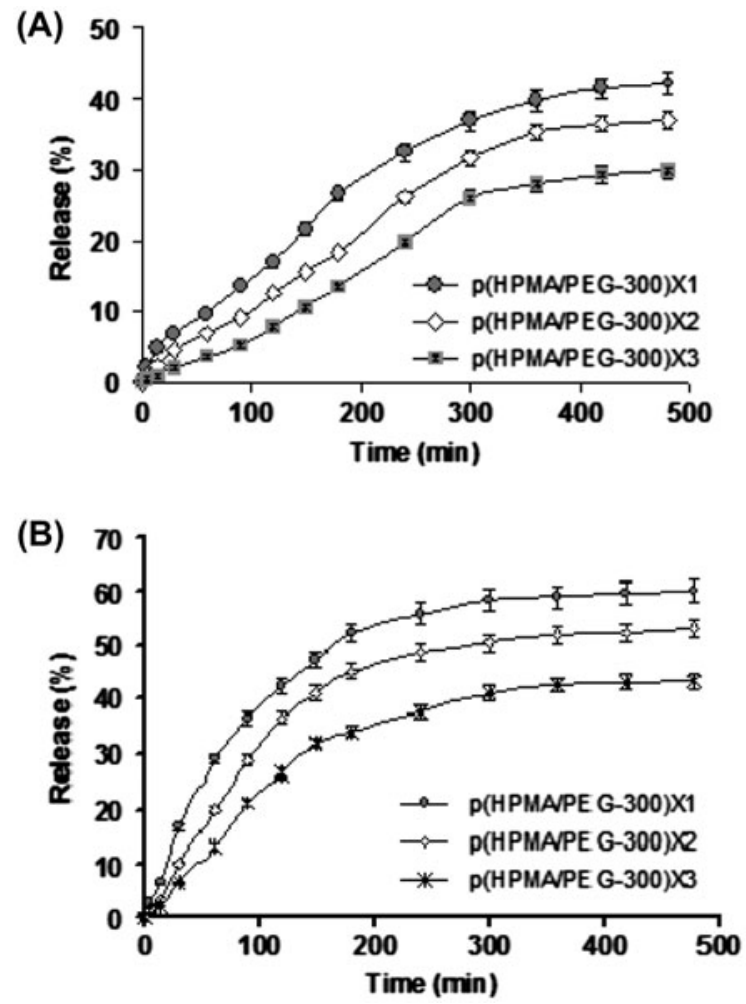

Figure 6. The effect of the cross-linker density on the doxorubicin release kinetics for the p(HPMA/PEG-300)X1, p(HPMA/PEG-300)X2, and p(HPMA/PEG-300)X3; (A) at $0.5 \mathrm{mg} / \mathrm{mL}$, and $(B)$ at $1.0 \mathrm{mg} / \mathrm{mL}$ drug loading. (The data presented in the graphs show the average values of three experiments, and the $p$-value $>0.05$ was used in the statistical analysis.) 


$$
\begin{gathered}
M_{t}=M_{\infty} k_{0} t \\
M_{t}=M_{\infty} e^{k t} \\
M_{t}=M_{\infty} k_{H} t^{1 / 2} \\
M_{t}=M_{\infty} K_{K P} t^{n} \\
\left(M_{t}-M_{\infty}\right)^{1 / 3}=k_{H C} t
\end{gathered}
$$

where $M_{t}$ and $M_{\infty}$ are the respective mass of drug release at time $t$ and infinite (equilibrium) time, respectively. $n$ is the diffusion exponent and related to drug release kinetics. $\mathrm{k}_{\mathrm{o}}, \mathrm{k}_{1}, k_{H}, K_{K P}$, and $k_{H C}$ are kinetic constants, $t$ is the release time, and $n$ is the diffusional exponent that can be related to the drug transport mechanism. For a thin hydrogel film, when $n=0.5$, the drug release mechanism is Fickian diffusion. When $n=1$, Case II transport occurs, leading to zero-order release. When the value of $n$ is between 0.5 and 1.0, anomalous transport is observed.[43,44] The mathematical theory of diffusion in isotropic substances is based on the hypothesis that the rate of transfer of the diffusing substance through a unit area of a section is proportional to the concentration gradient measured normal to the section, that is, Fick's first law of diffusion. Information about the release mechanism can be gained by fitting the drug release data and comparing the value of $n$ to the semi-empirical value of various geometry's reported by Peppas (11). The early-time (Equation (10)) and late-time (Equation (11)) approximation release equations are approximations of the equation that one obtains when solving Fick's second law of diffusion under initial and boundary conditions equivalent to those of testing in this work [44]:

$$
\begin{gathered}
M_{t} / M_{\infty}=4\left(D_{E} t / \pi \delta^{2}\right)^{0.5} \\
M_{t} / M_{\infty}=1-\left(8 / \pi^{2}\right) \exp \left(-\pi^{2} D_{L} t / \delta^{2}\right)^{0.5}
\end{gathered}
$$

where $M_{t} / M_{\infty}$ is the fractional drug release, $\mathrm{t}$ is the release time, $D_{E}$ and $D_{L}$ are the corresponding diffusional coefficients, and $\delta$ is the diffusional distance (film thickness). Evaluation of doxorubicin release kinetics from hydrogels was performed by calculating the diffusion coefficients $\left(D_{E}\right.$ and $\left.D_{L}\right)$ using the early-time and late-time approximation release equations. A plot of $M_{t} / M_{\infty}$ vs. $t^{0.5} / \delta$ is initially linear and from the slope of early-time approximation equation $D_{E}$ can be evaluated. A plot of $\log$ $\left[\left(\pi^{2} / 8\right)\left(1-M_{t} / M_{\infty}\right)\right]$ vs. $t$ is linear and from the slope of late-time approximation equation $D_{L}$ can be evaluated.

The diffusion coefficients, $D_{E}$ and $D_{L}$ of doxorubicin from the hydrogels were analyzed using Equations (10) and (11) and the results are given in Table 4. The goodness of fit in different release kinetic models (zero-order, first-order, Higuchi, Hixon-Crowell and Korsmeyer-Peppas 'power-law') was evaluated to understand the mechanism of drug release (Tables 5 and 6). The zero- and first-order release mechanisms could not be found to be valid for $\mathrm{p}(\mathrm{HPMA} / \mathrm{PEG}-950-300) \mathrm{X} 1$, and $\mathrm{p}(\mathrm{HPMA} / \mathrm{PEG}-300)-\mathrm{X} 1-\mathrm{X} 3$, hydrogel formulations with a drug loading $1.0 \mathrm{mg} / \mathrm{mL}$ (Table 5). The high values of the coefficient of linear regression $\left(R^{2}>0.95\right)$ for the Higuchi, Hixon-Crowell, and Korsmeyer-Peppas models confirmed that these analysis are valid for hydrogel films with two different drug loading concentrations (Table 6). The correlation coefficients for the Hixon-Crowell and Korsmeyer-Peppas models were higher than those for the Higuchi 
model for all the hydrogel films. The doxorubicin release mechanisms from hydrogel films of $\mathrm{p}(\mathrm{HPMA} / \mathrm{PEG}-300) \mathrm{X} 1-\mathrm{X} 3$, and $\mathrm{p}$ (HPMA/PEG-950-300)X1, were evaluated, and the $n$ values were observed to be between 0.53 and 0.86 (Table 6). Thus, the in vitro release mechanism in the hydrogel film formulations could therefore be described by anomalous transport mechanism. In addition, the $n$ values related to drug release kinetics were in all cases lower than 1 in all cases, and this indicated that drug release was not time-dependent and controlled by the relaxation process due to the swelling of the polymeric network. The values of model release parameters $n$ and $K_{K P}$ (rate constant) are inversely related. A higher value of $K_{K P}$ may suggest burst drug release from the polymeric hydrogel networks. The $D_{E}$ values of doxorubicin from the hydrogel films with different PEG chains length were analyzed with Equation (10) and the results are given in Table 4 . The $D_{E}$ values of the hydrogel films of $\mathrm{p}$ (HPMA/PEG950-300)X1, were found to be $8.7 \times 10^{-7}, 12.8 \times 10^{-7}$, and $18.5 \times 10^{-7} \mathrm{~cm}^{2} / \mathrm{s}$, respectively. The same trend was observed for the $D_{L}$ values (Table 4). As observed in the table, the $D_{E}$ and $D_{L}$ values decreased as the chains length of PEG increased in the hydrogel formulations. Figures 5 and 6 show the effect of the drug loading on the release pattern as a function of time for hydrogel films of $\mathrm{p}(\mathrm{HPMA} / \mathrm{PEG}-950-300) \mathrm{X} 1$, and $\mathrm{p}(\mathrm{HPMA} / \mathrm{PEG}-300)-\mathrm{X} 1-\mathrm{X} 3$. In all the samples, at any given time, the drug release increased with an increase in the percent loading of the doxorubicin in the hydrogel films at $\mathrm{pH} 7.4$ and at $37^{\circ} \mathrm{C}$. As shown in Figure 5, the release of doxorubicin from each hydrogel formulation was nearly linear in the first $2.0 \mathrm{~h}$, and this suggested an almost constant rate of doxorubicin release during this period. The hydrogel formulations had similar release profiles, despite different doxorubicin contents. This indicates that at a lower drug concentration, most of the drug molecules remained bound to the polymeric chains of the hydrogels, whereas at a higher drug concentration, the percentage of unbound drug molecules increased in the polymer networks. The maximum doxorubicin release for the $\mathrm{p}(\mathrm{HPMA} / \mathrm{PEG}-950) \mathrm{X} 1$ hydrogel formulation with different drug amounts loaded $(0.5$ and $1.0 \mathrm{mg} / \mathrm{mL})$ was determined to be 61.3 and $98.3 \%$ after $480 \mathrm{~min}$, respectively. Doxorubicin is freely soluble in a physiological phosphate buffer $(\mathrm{pH} 7.4)$; as a result, the rate of depletion of the drug in the polymer at a high concentration was faster than at a low concentration. In this process, the hydrogel became more permeable at a high drug concentration, and this increased the diffusion constant of the drug in the polymer network.[30,31] In Table 4, the diffusion constant of the drug was observed to be much lower for $1.0 \mathrm{mg} / \mathrm{mL}$ drug-loaded p(HPMA/PEG-950)X1 films than for the other hydrogel formulations.

Table 4. Doxorubicin diffusion coefficients calculated with the early-time and late-time approximation release equations and for the different molecular weight of PEG and cross-linked ratio carrying $\mathrm{p}(\mathrm{HPMA} / \mathrm{PEG}-\mathrm{MEMA})$ hydrogel formulations.

\begin{tabular}{lcccc}
\hline Formulation & $D_{E}\left(\mathrm{~cm}^{2} \mathrm{~s}^{-1}\right) \times 10^{7}$ & $R^{2}$ & $D_{L}\left(\mathrm{~cm}^{2} \mathrm{~s}^{-1}\right) \times 10^{7}$ & $R^{2}$ \\
\hline p(HPMA/PEG-950)X1 & 8.70 & 0.868 & 14.7 & 0.975 \\
p(HPMA/PEG-475)X1 & 12.8 & 0.906 & 15.9 & 0.985 \\
p(HPMA/PEG-300)X1 & 18.5 & 0.957 & 18.3 & 0.999 \\
p(HPMA/PEG-300)X2 & 21.0 & 0.959 & 19.4 & 0.998 \\
p(HPMA/PEG-300)X3 & 22.5 & 0.972 & 20.9 & 0.976 \\
\hline
\end{tabular}


Table 5. Zero- and first-order Doxorubicin release kinetic of the different molecular weight of PEG and cross-linked ratio carrying p(HPMA/PEG-MEMA) hydrogel formulations.

\begin{tabular}{lccccc}
\hline & \multicolumn{2}{c}{ Zero order } & & \multicolumn{2}{c}{ First order } \\
\cline { 2 - 3 } \cline { 5 - 6 } Formulation & $\mathrm{k}_{0} \times 10^{3}\left(\mathrm{~min}^{-1}\right)$ & $R^{2}$ & & $\mathrm{k} \times 10^{3}(\mathrm{~min})$ & $R^{2}$ \\
\hline p(HPMA/PEG-950)X1 & 1.19 & 0.733 & & 2.07 & 0.618 \\
p(HPMA/PEG-475)X1 & 1.50 & 0.791 & & 2.89 & 0.673 \\
p(HPMA/PEG-300)X1 & 1.86 & 0.864 & & 4.31 & 0.713 \\
p(HPMA/PEG-300)X2 & 1.99 & 0.876 & & 5.24 & 0.724 \\
p(HPMA/PEG-300)X3 & 2.11 & 0.904 & & 5.72 & 0.749 \\
\hline
\end{tabular}

Table 6. Higucci, Hixson-Crowell, and Korsmeyer-Peppas Doxorubicin release parameters for the different molecular weight of PEG and cross-linked ratio carrying p(HPMA/PEG-MEMA) hydrogel formulations.

\begin{tabular}{|c|c|c|c|c|c|c|c|}
\hline \multirow[b]{2}{*}{ Formulation } & \multicolumn{2}{|c|}{ Higucci } & \multicolumn{2}{|c|}{ Hixson-Crowell } & \multicolumn{3}{|c|}{ Korsmeyer-Peppas } \\
\hline & $\begin{array}{l}k_{H} \times 10^{2} \\
\left(\min ^{-1 / 2}\right)\end{array}$ & $R^{2}$ & $\begin{array}{l}k_{H C} \times 10^{2} \\
\left(\min ^{-1 / 3}\right)\end{array}$ & $R^{2}$ & $\begin{array}{c}K_{K P} \times 10^{2} \\
\left(\min ^{-n}\right)\end{array}$ & $n$ & $R^{2}$ \\
\hline p(HPMA/PEG-950)X1 & 3.50 & 0.860 & 0.71 & 0.968 & 1.40 & 0.53 & 0.974 \\
\hline $\mathrm{p}(\mathrm{HPMA} / \mathrm{PEG}-475) \mathrm{X} 1$ & 4.29 & 0.906 & 0.75 & 0.976 & 7.22 & 0.57 & 0.980 \\
\hline $\mathrm{p}(\mathrm{HPMA} / \mathrm{PEG}-300) \mathrm{X} 1$ & 5.12 & 0.953 & 0.76 & 0.988 & 2.24 & 0.67 & 0.978 \\
\hline $\mathrm{p}(\mathrm{HPMA} / \mathrm{PEG}-300) \mathrm{X} 2$ & 5.45 & 0.958 & 0.72 & 0.986 & 1.04 & 0.81 & 0.969 \\
\hline $\mathrm{p}(\mathrm{HPMA} / \mathrm{PEG}-300) \mathrm{X} 3$ & 5.64 & 0.972 & 0.73 & 0.999 & 0.75 & 0.86 & 0.985 \\
\hline
\end{tabular}

\subsection{Cytotoxicity studies using $\mathrm{LDH}$ release test.}

Lactate dehydrogenase (LDH) test was performed to determine the cytotoxicity of the hydrogel formulations. SNU398 cells were seeded in 96-wells plates as reported for the LDH assay. Percentage of cell viability was calculated by comparison to $0 \%$ viability (positive control) and 100\% viability of untreated cells. All experiments were performed in triplicate. As shown in Figure 7, all hydrogel formulations showed low cytotoxicity to SNU398 cells, and the relative cell toxicity of the hydrogels was lower than $7 \%$. Altogether, no clear difference between hydrogel formulations was observed with regard to cytotoxicity. Variability of the cytotoxicity values was the smallest with the hydrogel formulation except that $\mathrm{p}$ (HPMA-PEG-950)-X1 formulation had no cytotoxic effect on the SNU398 cells. The lower cytotoxicity of hydrogels should be attributed to the presence of large quantity of water in the network. The low cytotoxicity to SNU398 cell line suggested that these hydrogel formulations could be used as excellent drug carrier material for the future biomedical application.

\subsection{In vitro antitumor activity}

Hydrogels are cross-linked hydrophilic polymer. They are an important class of biomaterials, and have been used in several biotechnological and biomedical applications.[6, 10-20] In this study, we prepared a series of hydrogel with different PEG chains length and cross-linking density to be used as implant drug release system. Doxorubicin, one of most widely used anticancer drug was selected as the model drug-loaded inside these hydrogel formulations, to investigate the drug release rates and in vitro cytotoxicity 


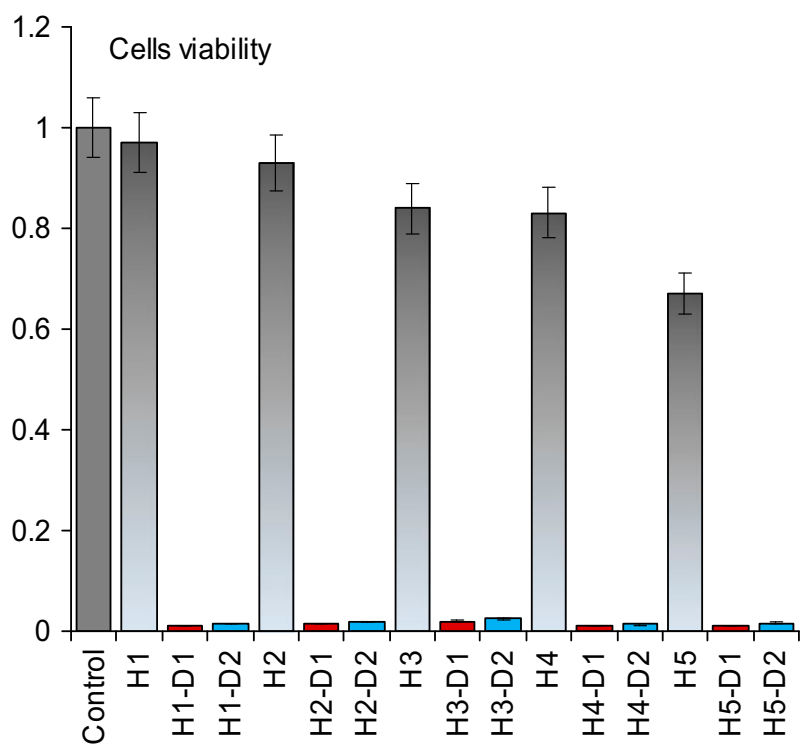

Figure 7. Cytotoxicity to SNU398 cells, and the relative cell toxicity of the all hydrogel formulations. (The data presented in the graphs show the average values of the at least three experiments, and the $p$-value $>0.05$ was used in the statistical analysis.)

Notes: H1: p(HPMA/PEG-950)X1 hydrogel; H2: p(HPMA/PEG-475)X1; H3: p(HPMA/PEG-300) X1; H4: p(HPMA/PEG-300)X2; H5: p(HPMA/PEG-300)X3; D1: $0.5 \mathrm{mg} / \mathrm{mL}$ doxorubicin loaded; D2: $1.0 \mathrm{mg} / \mathrm{mL}$ doxorubicin loaded.

on SNU398 cells. The cytotoxicity test was used to evaluate in vitro antitumor activity of doxorubicin loaded hydrogel formulations using doxorubicin free hydrogel counterpart formulation as control system. The cytotoxicities of $\mathrm{p}(\mathrm{HPMA} / \mathrm{PEG}-950) \mathrm{X} 1-\mathrm{D}, \mathrm{p}(\mathrm{HPMA} /$

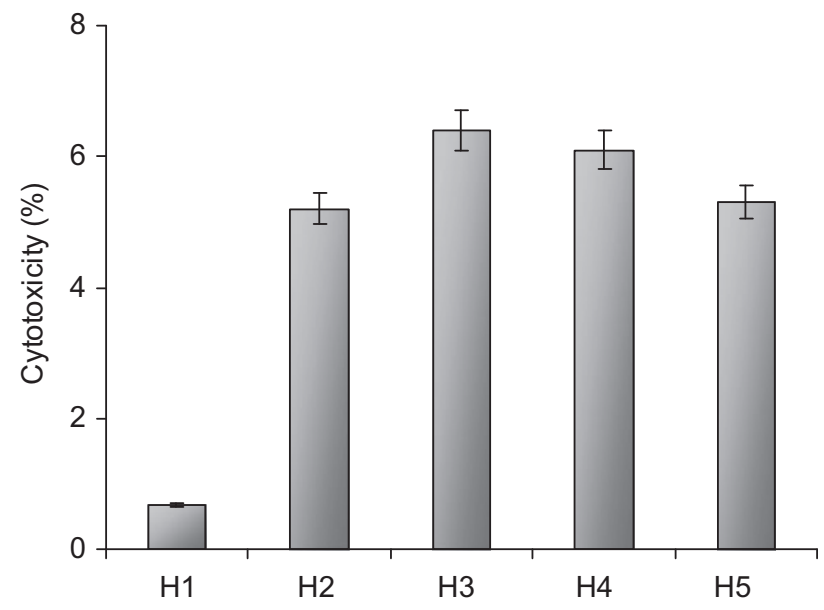

Figure 8. The variation of cell viability against two different drug concentrations. (The data presented in the graphs show the average values of the at least three experiments, and the $p$-value $>0.05$ was used in the statistical analysis.)

Notes: H1: p(HPMA/PEG-950)X1 hydrogel; H2: p(HPMA/PEG-475)X1; H3: p(HPMA/PEG-300) X1; H4: p(HPMA/PEG-300)X2; H5: p(HPMA/PEG-300)X3. 
PEG-475)X1-D, p(HPMA/PEG-300)X1-D, p(HPMA/PEG-300)X2-D, or p(HPMA/PEG300)X3-D were performed against human hepatocellular carcinoma (SNU398) cells. The variations of cell viability against two different drug concentrations were shown in Figure 8 . The cell viabilities of the doxorubicin free hydrogel formulations for SNU398 cells were all above $80 \%$, which clearly indicated that the blank hydrogel has no apparent cytotoxicity on SNU398 cells, showing the good biocompatibility of these hydrogel formulations. To evaluate and compare the in vitro cytotoxicity of the drug-loaded hydrogel formulation, the hydrogel formulations with two different concentrations of drug loading (i.e. 0.5 and $1.0 \mathrm{mg} / \mathrm{g}$ hydrogel) were used to determine the cell viability during six days incubation periods. After six days incubation period, the cell viabilities were less than $0.02 \%$ for all doxorubicin-loaded hydrogels. Doxorubicin released from the hydrogels with two different concentrations of drug loading have biological activities and show high cytotoxicity to the SNU398 cells. With the increase in initial drug concentration, the cytotoxicity of the drug-loaded hydrogel enhances.

\section{Conclusions}

Biocompatibility property makes hydrogels a useful delivery platform for the development of localized chemotherapy. Modifying the properties of hydrogels by changing PEG chains length and cross-linking density provided control over doxorubicin release rates. This study demonstrated that $\mathrm{p}$ (HPMA/PEG-MEMA)-based hydrogel formulations can serve as valuable local delivery platform for cancer research and therapy. The in vitro cytotoxicity of the hydrogels was demonstrated to be low since LDH leakage from the cells was less than $7 \%$ for all the tested hydrogel formulations.

\section{References}

[1] Schoener CA, Peppas NA. pH-responsive hydrogels containing PMMA nanoparticles: an analysis of controlled release of a chemotherapeutic conjugate and transport properties. J. Biomater. Sci., Polym. Ed. 2013;24:1027-1040.

[2] Bhattarai N, Gunn J, Zhang M. Chitosan-based hydrogels for controlled, localized drug delivery. Adv. Drug Delivery Rev. 2010;62:83-99.

[3] Li Y, Huang G, Zhang X, Li B, Chen Y, Lu T, Lu TJ, Xu F. Magnetic hydrogels and their potential biomedical applications. Adv. Funct. Mater. 2013;23:660-672.

[4] Tomić SLJ, Mićić MM, Filipović JM, Suljovrujić EH. Synthesis, characterization and controlled release of cephalexin drug from smart poly(2-hydroxyethyl methacrylate/poly (alkylene glycol)(meth)acrylates hydrogels. Chem. Eng. J. 2010;160:801-809.

[5] Guiseppi-Elie A. Electroconductive hydrogels: synthesis, characterization and biomedical applications. Biomaterials. 2010;31:2701-2716.

[6] Oelker AM, Morey SM, Griffith LG, Hammond PT. Helix versus coil polypeptide macromers: gel networks with decoupled stiffness and permeability. Soft Matter. 2012;8:10887-10895.

[7] Yang L, Guiseppi-Wilson A, Guiseppi-Elie A. Design considerations in the use of interdigitated microsensor electrode arrays (IMEs) for impedimetric characterization of biomimetic hydrogels. Biomed. Microdevices. 2011;13:279-289.

[8] Bayramoglu G, Arica MY. P(HPMA/EGDMA) beads grafted with fibrous chains by SI-ATRP method: Agmatine functionalized affinity beads for selective separation of serum albumin. Bioprocess Biosyst Eng. 2014;37:205-215.

[9] Zhao C, Li L, Wang Q, Yu Q, Zheng J. Effect of film thickness on the antifouling performance of poly(hydroxy-functional methacrylates) grafted surfaces. Langmuir. 2011;27:4906-4913.

[10] Wang W, Zhang P, Shan W, Gao J, Liang W. A novel chitosan-based thermosensitive hydrogel containing doxorubicin liposomes for topical cancer therapy. J. Biomater. Sci., Polym. Ed. 2013;24:1649-1659. 
[11] Huynh CT, Nguyen MK, Jeong IK, Kim SW, Lee DS. Synthesis, characteristics and potential application of poly( $\beta$-amino ester urethane)-based multiblock co-polymers as an injectable, biodegradable and $\mathrm{pH} /$ temperature-sensitive hydrogel system. J. Biomater. Sci., Polym. Ed. 2012;23:1091-1106.

[12] Arıca MY, Tuğlu D, Başar MM, Kılıç D, Bayramoğlu G, Batislam E. Preparation and characterization of infection-resistant antibiotics-releasing hydrogel rods of poly(hydroxyethyl methacrylate/(poly(ethylene glycol)-methacrylate): biomedical application in a novel rabbit penile prosthesis model. J. Biomed. Mater. B. 2008;86B:18-22.

[13] Bayramoglu G, Akcalı CK, Gultekin S, Bengu E, Arica MY. Preparation and characterization of poly(hydroxyethyl methacrylate-co-poly(ethyleneglycolmethacrylate)/hydroxypropylchitosan hydrogel films: adhesion of rat mesenchymal stem cells. Macromol. Res. 2011;19: 385-395.

[14] Zhu W, Li Y, Liu L, Chen Y, Xi F. Supramolecular hydrogels as a universal scaffold for stepwise delivering Dox and Dox/cisplatin loaded block copolymer micelles. Int. J. Pharm. 2012;437:11-19.

[15] Seib FP, Pritchard EM, Kaplan DL. Self-assembling doxorubicin silk hydrogels for the focal treatment of primary breast cancer. Adv. Funct. Mater. 2013;23:58-65.

[16] Bayramoğlu G, Batislam E, Arica MY. Preparation and drug-release behavior of minocycline-loaded poly[hydroxyethyl methacrylate-co-poly(ethylene glycol)-methacrylate] films. J. Appl. Polym. Sci. 2009;112:1012-1020.

[17] Dadsetan M, Liu Z, Pumberger M, Giraldo CV, Ruesink T, Lu L, Yaszemski MJ. A stimuli-responsive hydrogel for doxorubicin delivery. Biomaterials. 2010;31:8051-8062.

[18] Tan H, Luan H, Hu Y, Hu X. Covalently crosslinked chitosan-poly(ethylene glycol) hybrid hydrogels to deliver insulin for adipose-derived stem cells encapsulation. Macromol. Res. 2013;21:392-399.

[19] Azzahari AD, Yahya R, Hassan A, Sheikh Md RK. Synthesis and characterization of new copolymers from glycidyl methacrylate and tetrahydrofurfuryl acrylate: determination of reactivity ratios. Fibers Polym. 2012;13:555-563.

[20] Wang K, Li WF, Xing JF, Dong K, Gao Y. Preliminary assessment of the safety evaluation of novel pH-sensitive hydrogel. Eur. J. Pharm. Biopharm. 2012;82:332-339.

[21] Biondi M, Fusco S, Lewis AL, Netti PA. New insights into the mechanisms of the interactions between doxorubicin and the ion-exchange hydrogel DC Bead ${ }^{\mathrm{TM}}$ for use in transarterial chemoembolization (TACE). J. Biomater. Sci., Polym. Ed. 2012;23:333-354.

[22] Sishi BJN, Loos B, van Rooyen J, Engelbrecht A-M. Doxorubicin induces protein ubiquitination and inhibits proteasome activity during cardiotoxicity. Toxicology. 2013;309:23-29.

[23] Dadsetan M, Taylor KE, Yong C, Bajzer Željko, Lu L, Yaszemski MJ. Controlled release of doxorubicin from pH-responsive microgels. Acta Biomater. 2013;9:5438-5446.

[24] Cui Y, Li Y, Duan Q, Kakuchi T. Preparation of hyaluronic acid micro-hydrogel by biotinavidin-specific bonding for doxorubicin-targeted delivery. Appl. Biochem. Biotechnol. 2013;169:239-249.

[25] Schoener CA, Peppas NA. Oral delivery of chemotherapeutic agents: background and potential of drug delivery systems for colon delivery. J. Drug Del. Sci. Technol. 2012;22:459-468.

[26] Wang Y, Zhang X, Yu P, Li C. Glycopolymer micelles with reducible ionic cores for hepatocytes-targeting delivery of DOX. Int. J. Pharm. 2013;441:170-180.

[27] Takei T, Sugihara K, Yoshida M, Kawakami K. Injectable and biodegradable sugar beet pectin/gelatin hydrogels for biomedical applications. J. Biomater. Sci., Polym. Ed. 2013;24:1333-1342.

[28] Wei L, Cai C, Lin J, Chen T. Dual-drug delivery system based on hydrogel/micelle composites. Biomaterials. 2009;30:2606-2613.

[29] Gehrke SH, Fisher JP, Palasis M, Lund ME. Factors determining hydrogel permeability. Ann. NY Acad. Sci. 1997;31:179-297.

[30] Bradford MM. Rapid and sensitive method for the quantitation of microgram quantities of protein utilizing the principle of protein-dye binding. Anal. Biochem. 1976;72:248-254.

[31] Bayramoglu G, Bitirim V, Tunali Y, Arica MY, Akcali KC. Poly(hydroxylethyl methacrylate glycidyl methacrylate) films modified with different functional groups: In vitro interactions with platelets and ratstem cells. Braz. J. Mat. Sci. Eng. C. 2013;33:801-810. 
[32] Bayramoğlu G, Yılmaz M, Batislam E, Arıca MY. Heparin-coated poly(hydroxyethyl methacrylate/albumin) hydrogel networks: In vitro hemocompatibility evaluation for vascular biomaterials. J. Appl. Polym. Sci. 2008;109:749-757.

[33] Sohn E-H, Lee M, Song K. Liquid crystal alignment behaviors and wetting properties of polymer blend surfaces. Macromol. Res. 2013;21:234-241.

[34] Arıca MY, Bayramolu G, Arıca B, Yalçın E, Ito K, Yagci Y. Novel hydrogel membrane based on copoly(hydroxyethyl methacrylate/p-vinylbenzyl-poly(ethylene oxide)) for biomedical applications: properties and drug release characteristics. Macromol. Biosci. 2005;5:983-992.

[35] Jin J, Jiang W, Yin J, Ji X, Stagnaro P. Plasma proteins adsorption mechanism on polyethylene-grafted poly(ethylene glycol) surface by quartz crystal microbalance with dissipation. Langmuir. 2013;29:6624-6633.

[36] Michel R, Pasche S, Textor M, Castner DG. Langmuir. The influence of PEG architecture on protein adsorption and conformation. 2005;21:12327-12332.

[37] Ostaci R-V, Damiron D, Akhrass SA, Grohens Y, Drockenmuller E. Poly (ethylene glycol) brushes grafted to silicon substrates by click chemistry: influence of PEG chain length, concentration in the grafting solution and reaction time. Polym. Chem. 2011;2:348-354.

[38] Xuan J-J, Yan Y-D, Oh DH, Choi YK, Yong CS, Choi H-G. Development of thermo-sensitive injectable hydrogel with sustained release of doxorubicin: Rheological characterization and in vivo evaluation in rats. Drug Delivery. 2011;18:305-311.

[39] Zarzhitsky S, Rapaport H, Colloid J. The interactions between doxorubicin and amphiphilic and acidic $\beta$-sheet peptides towards drug delivery hydrogels. Inter. Sci. 2011;360:525-531.

[40] Chirra HD, Hilt JZ. Nanoscale characterization of the equilibrium and kinetic response of hydrogel structures. Langmuir. 2010;26:11249-11257.

[41] Srikar R, Yarin AL, Megaridis CM, Bazilevsky AV, Kelley E. Desorption-limited mechanism of release from polymer nanofibers. Langmuir. 2008;24:965-974.

[42] Xu S, Zeng R, Cheng J, Cai Z, Wen X, Pi P. Preparation of antimicrobial polycarboxybetaine-based hydrogels for studies of drug loading and release. J. Appl. Polym. Sci. 2014;131:39839-39840.

[43] Ritger PL, Peppas NA. A simple equation for description of solute release. I. Fickian and non-Fickian release from non-swellable devices in the form of slabs, spheres, cylinders or discs. J. Controlled Release. 1987;5:23-36.

[44] Serra L, Domenech J, Peppas NA. Drug transport mechanisms in and release kinetics from molecularly designed p(acrylic acid-g-ethyleneglycol) hydrogels. Biomaterials. 2006;27: $5440-5451$. 